\title{
The pattern of cervical smear abnormalities in marginalised women in Hong Kong
}

\author{
YH Ting *, HY Tse, WC Lam, KS Chan, TY Leung
}

\section{A B S T R A C T}

Introduction: "Ripple Action" and "WE Stand" are projects co-organised by the Hong Kong Women Doctors Association. The two projects organise free cervical screening for low-income women, new immigrants from Mainland China, and ethnic minority women. The objective of this study was to analyse the pattern of cervical smear abnormalities in these marginalised women.

Methods: The study group consisted of 1189 marginalised women who participated in a free cervical screening campaign, including 324 lowincome local Chinese, 540 new immigrants from Mainland China, and 325 ethnic minority women. The comparison group consisted of 1141 local Chinese who attended a well women clinic. The prevalence of cervical smear abnormalities was compared using Chi squared test.

Results: In the study group, $42.6 \%$ of women had never had a cervical smear. Compared with the comparison group, they had a significantly higher prevalence of cervical smear abnormalities $(13.7 \%$ vs $1.4 \% ; \mathrm{P}<0.001)$, including atypical smear $(10.8 \%$ vs $0.5 \%$; $\mathrm{P}<0.001)$, low-grade lesion $(1.8 \%$ vs $0.8 \%$; $\mathrm{P}=0.036)$, and high-grade lesion $(1.1 \%$ vs $0.1 \%$; $\mathrm{P}=0.002)$. Logistic regression analysis showed that the strongest predictors for abnormal cervical smear were being South Asian (odds ratio=11.859; 95\% confidence interval, 4.635-30.341), South-East
Mainland China (6.253; 2.463-15.877).

Conclusions: Marginalised women had a significantly higher prevalence of cervical smear abnormality than the general population and almost half had never had a cervical smear before. Outreach strategies are needed to enrol this population into screening programmes.

\author{
Hong Kong Med J 2017;23:28-34 \\ DOI: $10.12809 / \mathrm{hkmj} 164887$

\footnotetext{
${ }^{1}$ YH Ting *, FRCOG, FHKAM (Obstetrics and Gynaecology)

2 HY Tse, FRCOG, FHKAM (Obstetrics and Gynaecology)

${ }^{3}$ WC Lam, MPH (CUHK), FHKAM (Obstetrics and Gynaecology)

${ }^{4}$ KS Chan, FRCOG, FHKAM (Obstetrics and Gynaecology)

${ }^{5}$ TY Leung, LMCHK; DCOGHK
} \\ 1 Department of Obstetrics and Gynaecology, The Chinese University of \\ Hong Kong, Prince of Wales Hospital, Shatin, Hong Kong \\ ${ }^{2}$ Magnus MRI and Ultrasound Diagnostic Center, Hermes Commercial \\ Centre, Tsimshatsui, Hong Kong \\ ${ }^{3}$ Department of Obstetrics and Gynaecology, Tseung Kwan O Hospital, \\ Tseung Kwan O, Hong Kong \\ ${ }^{4}$ Department of Obstetrics and Gynaecology, Kwong Wah Hospital, \\ Yaumatei, Hong Kong \\ ${ }^{5}$ Well Women Clinic, Tung Wah Group of Hospitals, Yaumatei, Hong Kong
}

An earlier version of this paper was presented at the 29th International Congress of the Medical Women's International Association held in Ewha Woman's University, Seoul, Korea on 31 July to 3 August 2013.

Asian (6.484; 3.192-13.171), or new immigrant from * Corresponding author: tingyh@cuhk.edu.hk

New knowledge added by this study

- Of the marginalised women studied, $42.6 \%$ have never had a cervical smear.

- Marginalised women have a significantly higher prevalence of cervical smear abnormality than the general population.

- South Asian, South-East Asian, and new immigrants from Mainland China have a 6- to 11-fold increased risk of cervical smear abnormalities compared with the local Chinese population.

Implications for clinical practice or policy

- The Government should be proactive in developing a more comprehensive cervical cancer screening programme in Hong Kong.

- The Government should ensure adequate cervical cancer screening coverage for marginalised women in Hong Kong by developing community outreach programmes through collaboration with non-governmental organisations in the community.

\section{Introduction}

Cervical cancer is an important global health problem in women. It is the fourth most common cancer in women worldwide with an age-standardised rate (ASR) of 14.2 per $100000 .{ }^{1}$ Cervical screening and treatment of precancerous lesions have been shown to reduce the incidence and mortality of cervical cancer in many developed countries. This remarkable success has been achieved through organised screening programmes. Such programmes, however, 
are not routinely available in most developing countries. $^{2,3}$

\section{Cervical cancer screening in Hong Kong}

An organised cervical cancer screening programme was launched in Hong Kong in 2004 for 25- to 64-year-old women who were currently or previously had been sexually active. ${ }^{4}$ The programme does not proactively recruit eligible women who have never had a cervical smear. These women must seek cervical smear services by themselves from family health service clinics, well women clinics, general practitioners, or private gynaecologists for their first smear before they can be registered under the programme and become eligible for recall for subsequent smears. Of eligible women in Hong Kong, 30\% have yet to have a cervical smear, despite the availability of the scheme for 11 years. ${ }^{5}$ The most common reasons cited were cost, lack of time, ignorance about cervical cancer and screening, lack of knowledge about how to access the screening service, and embarrassment. ${ }^{6-9}$ These reasons were particularly common for marginalised women.

\section{'Ripple Action' and 'WE Stand'}

'Ripple Action' is a collaborative project launched by several women professional bodies to serve the marginalised women in Hong Kong. Collaborating parties include doctors, nurses, lawyers, accountants, social workers, and various local women organisations. 'WE Stand' is a project launched by RainLily in collaboration with the Hong Kong Women Doctors Association to raise the awareness about sexual violence against foreign female workers and ethnic minority women. These two projects organise free cervical screening events for lowincome women, new immigrants from Mainland China, and ethnic minority women. The objective of this study was to analyse the pattern of cervical smear abnormalities in these marginalised women.

\section{Methods}

The study group consisted of women who had a cervical smear taken in one of the 16 free cervical screening events held between March 2008 and November 2014. These women were recruited by various charitable non-governmental organisations (NGOs) and included low-income local Chinese women in receipt of assistance from NGOs, new immigrants from Mainland China who had lived in Hong Kong for less than 7 years, and ethnic minority women mainly from South Asia and South-East Asia. Demographic data, including age, self-reported ethnicity, date of last menstrual period, and history of cervical smear were recorded. Menstruating women and those with a hysterectomy or no sexual history were excluded from screening. Informed consent for

\section{香港邊緣女性宮頸塗片異常的比率 \\ 丁婉霞、謝喜兒、林慧翔、陳潔霜、梁冬陽}

引言：「漣渏行動」和「凝 ·動」是由香港女醫生協會協辦的項目。 這兩個項目的服務對象是低收入婦女、來自中國大陸的新移民和少數 族裔婦女, 為她們提供免費宮頸癌穊查。本研究旨在分析邊緣女性宮 頸塗片異常的情況

方法：研究組別為1189名參加了免費宮頸癌節查活動的邊緣女性, 包 括324名低收入華籍婦女、來自中國內地的540名新移民，以及325名 少數族裔婦女。對照組別為 1141 名於婦女健康普查部接受檢查的女 性。利用卡方檢驗比較兩個組別宮頸塗片異常的比率。

結果：研究組別中有 $42.6 \%$ 的婦女從未接受宮頸塗片檢查。與對照 組比較, 研究組別中宮頸塗片異常的比率較高（13.7\%比 $1.4 \%$; $\mathrm{P}<0.001)$ ，其中包括非典型塗片（10.8\%比 $0.5 \% ; \mathrm{P}<0.001)$ 、低 度病變（ $1.8 \%$ 比 $0.8 \% ； \mathrm{P}=0.036)$ ，以及高度病變（ $1.1 \%$ 比 $0.1 \%$; $\mathrm{P}=0.002) 。$ 邏輯迴歸分析顯示宮頸塗片異常的最強預測因素為 南亞裔（比值比=11.859；95\%置信區間4.635-30.341）、東南亞裔 （6.484；3.192-13.171）或內地新移民（6.253；2.463-15.877）。

結論：邊緣女性的宮頸塗片異常比率比一般人口顯著較高，而且幾乎 一半從未接受子宮頸細胞檢驗。必需採取策略性方法向她們推廣宮頸 癌普查計劃。

cervical smear taking was obtained. Cervical smears were processed using the ThinPrep Pap Test liquidbased system in an accredited cytology laboratory and examined by accredited cytopathologists at a private hospital. All cervical smear reports were reviewed by specialist gynaecologists. Women with a normal cervical smear were called to collect the report in person from the referring NGO. Women with a cervical smear abnormality were individually counselled by a specialist gynaecologist. Women with atypical smears were referred to a family health service clinic for a follow-up smear. Women with epithelial lesions were referred to the gynaecology department in a public hospital.

The prevalence of cervical smear abnormalities in the study group was compared with a comparison group that comprised cervical smear reports selected from the database of a well women clinic in Hong Kong. The first 200 of every 1000 sequential smear reports taken in the four Februarys of the years 2011 to 2014 were selected. To ensure that these reports were from local Chinese population, reports bearing foreign names and those with the first alphabet of the identity card number being $\mathrm{R}$ (holders arrived Hong Kong from 2000 to 2011), M (holders arrived after 2011), or W (foreign workers) were excluded. Unsatisfactory smears and vault smears were also excluded. Statistical analysis of the difference in the prevalence of cervical smear abnormalities between the study and the comparison groups was performed 
with Chi squared test using the Statistical Package for the Social Sciences (Windows version 22.0; SPSS Inc, Chicago [IL], US). A P value of $<0.05$ was regarded as statistically significant. Binary logistic regression analysis was performed to predict the odds of having a cervical smear abnormality using the following variables: (1) age; (2) resident in Hong Kong for less than 7 years; (3) never had a cervical smear before; (4) ethnicity including local Chinese (reference group), new immigrant from Mainland China, South-East Asian (Indonesian, Filipino, and Thai) or South Asian (Indian, Pakistani, Sri Lankan, Nepalese, and Bangladeshi). The study was approved by the Joint Chinese University of Hong Kong-New Territories East Cluster Clinical Research Ethics Committee (CREC Ref. No.: 2015.426).

\section{Results}

There were 1194 participants across the 16 free cervical screening events. Five women were excluded from cervical smear screening because of previous hysterectomy or current menstruation. Thus, the study group consisted of 1189 marginalised women, including 324 low-income local Chinese women who were receiving assistance from NGOs, 540 new immigrants from Mainland China who were residents in Hong Kong for less than 7 years, and 325 ethnic minority women mainly from South Asia and South-East Asia. The characteristics of the study group, including the self-reported ethnicity, history of cervical smear, and prevalence of cervical smear abnormalities are shown in Table 1. Among the 838 women with information available about a history of cervical smear, 357 (42.6\%) had never had a cervical smear. Compared with the local Chinese in the study group, there were significantly more ethnic minority women and new immigrants from Mainland China who had never had a cervical smear $(61.2 \%$ vs $45.4 \%$ vs $25.0 \% ; \mathrm{P}<0.001)$, and their prevalence of cervical smear abnormalities was also significantly higher (20.0\% vs $12.8 \%$ vs $9.0 \%$; $\mathrm{P}<0.001)$ [Table 1 ].

There were 163 women with cervical smear abnormalities in the study group, including 129 (79\%) atypical cells of unknown significance (ACUS), 21 (13\%) low-grade squamous intraepithelial lesion (LSIL), and 13 (8\%) high-grade squamous intraepithelial lesion (HSIL). Compared with the 1141 local Chinese women in the comparison group, the study group had a significantly higher proportion of women who had never had a cervical smear $(42.6 \%$ vs $0 \% ; \mathrm{P}<0.001)$, and a significantly higher prevalence of cervical smear abnormalities $(13.7 \%$ vs $1.4 \%$; $\mathrm{P}<0.001)$, including ACUS (10.8\% vs $0.5 \% ; \mathrm{P}<0.001)$, LSIL ( $1.8 \%$ vs $0.8 \% ; \mathrm{P}=0.036)$, and HSIL ( $1.1 \%$ vs $0.1 \% ; \mathrm{P}=0.002$ ) [Table 2]. Binary logistic regression analysis showed that the strongest predictors for abnormal cervical smear were being South Asian (odds ratio $[\mathrm{OR}]=11.859 ; 95 \%$ confidence interval [CI], 4.635-30.341), South-East Asian (OR=6.484; $95 \% \mathrm{CI}, 3.192-13.171)$, or a new immigrant from Mainland China $(\mathrm{OR}=6.253$; 95\% CI, 2.463-15.877) [Table 3].

We also compared the prevalence of cervical smear abnormalities in the study group with another

TABLE I. Characteristics of the 1189 participants of the free cervical screening campaign according to ethnicity

\begin{tabular}{lccc}
\hline Ethnicity & No. (\%) & $\begin{array}{c}\text { No. never had cervical smear/ } \\
\text { No. with data on previous } \\
\text { smear available (\%)* }\end{array}$ & $\begin{array}{c}\text { No) of abnormal } \\
\text { cervical smear }\end{array}$ \\
\hline Local Chinese receiving assistance from NGOs & $324(27.2)$ & $64 / 256(25.0) \dagger$ & $29(9.0) \dagger$ \\
\hline New immigrants from Mainland China (<7 years) & $540(45.4)$ & $181 / 399(45.4) \dagger$ & $69(12.8) \dagger$ \\
\hline Ethnic minorities & $325(27.3)$ & $112 / 183(61.2) \dagger$ & $65(20.0) \dagger$ \\
\hline Indonesia & $86(26.5)$ & $6 / 7(85.7)$ & $22(25.6)$ \\
\hline Philippines & $83(25.5)$ & $26 / 50(52.0)$ & $17(20.5)$ \\
\hline Pakistan & $70(21.5)$ & $41 / 63(65.1)$ & $12(17.1)$ \\
\hline Nepal & $56(17.2)$ & $33 / 52(63.5)$ & $8(14.3)$ \\
India & $11(3.4)$ & $6 / 11(54.5)$ & $4(36.4)$ \\
\hline Thailand & $9(2.8)$ & - & $1(11.1)$ \\
\hline Arabia & $5(1.5)$ & - & 0 \\
\hline Sri Lanka & $3(0.9)$ & - & 0 \\
\hline Bangladesh & $1(0.3)$ & - & 0 \\
\hline Egypt & $1(0.3)$ & - & $1(100)$ \\
\hline Total & 1189 & $357 / 838(42.6)$ & $163(13.7)$ \\
\hline
\end{tabular}

Abbreviation: $\mathrm{NGOs}=$ non-governmental organisations

* Information on previous cervical smear was not available in 35 I women

† Chi squared test: $P<0.001$ 
data set that consisted of 509439 cervical cytology tests first recorded among registered women in the Cervical Screening Information System (CSIS) from the Cervical Screening Programme of the Department of Health from 2004 to $2014 .^{10}$ Similar to the previous findings, the study group once again had a significantly higher prevalence of cervical smear abnormalities (13.7\% vs 6.3\%; $\mathrm{P}<0.001)$, including ACUS (10.8\% vs 4.0\%; $\mathrm{P}<0.001)$ and HSIL (1.1\% vs $0.4 \% ; \mathrm{P}=0.005)$ although the prevalence of
LSIL was not significantly different ( $1.8 \%$ vs $1.9 \%$; $\mathrm{P}=0.833$ ) [Table 4].

We attempted to contact those women with an abnormal cervical smear to ensure compliance with subsequent gynaecological assessment and treatment after the events and were successful in 58 (36\%) instances. Among the 47 women with ACUS, $30(64 \%)$ attended for subsequent assessment, three underwent colposcopy and one had loop excision. Of the six women with LSIL, five attended subsequent

TABLE 2. Prevalence of cervical smear abnormalities in the study group and the comparison group

\begin{tabular}{|c|c|c|c|}
\hline & \multicolumn{2}{|c|}{ No. (\%) of subjects* } & \multirow[t]{2}{*}{$P$ value } \\
\hline & Study group $(n=1189)$ & Comparison group $(n=1141)$ & \\
\hline Median (range) age (years) & $39(20-73)$ & $53(24-84)$ & $<0.001 \ddagger$ \\
\hline Never had cervical smear/information available† & $357 / 838(42.6)$ & 0/1058 (0) & $<0.001 \S$ \\
\hline Abnormal cervical smear & $163(13.7)$ & $16(1.4)$ & $<0.001 \S$ \\
\hline ASCUS or AGUS & $129(10.8)$ & $6(0.5)$ & $<0.001 \S$ \\
\hline LSIL & $21(1.8)$ & $9(0.8)$ & $0.036 \S$ \\
\hline HSIL or CA II & $13(1.1)$ & $1(0.1)$ & $0.002 \S$ \\
\hline \multicolumn{4}{|c|}{$\begin{array}{l}\text { Abbreviations: AGUS = atypical glandular cells of unknown significance; ASCUS = atypical squamous cells of unknown s } \\
\text { CA = carcinoma; HSIL = high-grade squamous intraepithelial lesion; LSIL = low-grade squamous intraepithelial lesion } \\
* \text { Unless otherwise stated } \\
\dagger \text { Information on previous cervical smear was not available in } 35 \text { I women } \\
\ddagger \text { Kruskal-Wallis test } \\
\S \text { Chi squared test } \\
\| \text { There was only one case of adenocarcinoma in the comparison group }\end{array}$} \\
\hline
\end{tabular}

TABLE 3. Binary logistic regression analysis of various predictor variables for cervical smear abnormalities

\begin{tabular}{lcc}
\hline Predictor variable & Odds ratio $\mathbf{9 5 \%}$ confidence interval) & P value \\
\hline South Asian & $11.859(4.635-30.341)$ & $<0.001$ \\
South-East Asian & $6.484(3.192-13.171)$ & $<0.001$ \\
New immigrant from Mainland China & $6.253(2.463-15.877)$ & $<0.001$ \\
Age & $0.979(0.957-1.002)$ & 0.079 \\
Never had cervical smear before & $1.058(0.678-1.650)$ & 0.805 \\
Resident in Hong Kong for $<7$ years & $0.697(0.315-1.540)$ & 0.372 \\
\hline
\end{tabular}

TABLE 4. Prevalence of cervical smear abnormalities in the study group and the data from the Cervical Screening Information System (CSIS) from the Cervical Screening Programme of the Department of Health

\begin{tabular}{lccc}
\hline & \multicolumn{2}{c}{ No. (\%) of subjects } & \multirow{2}{*}{ P value } \\
\cline { 2 - 3 } & Study group $(\mathbf{n = 1 1 8 9 )}$ & CSIS data $(\mathbf{n = 5 0 9 ~ 4 3 9 )}$ & \\
\hline Abnormal cervical smear & $163(13.7)$ & $32344(6.3)$ & $<0.001 \dagger$ \\
ASCUS or AGUS & $129(10.8)$ & $20377(4.0)$ & $<0.001 \dagger$ \\
LSIL & $21(1.8)$ & $9638(1.9)$ & $0.833 \dagger$ \\
HSIL or CA & $13(1.1)$ & $2329(0.4)$ & $0.005 \dagger$ \\
\hline
\end{tabular}

Abbreviations: AGUS = atypical glandular cells of unknown significance; ASCUS = atypical squamous cells of unknown significance;

$\mathrm{CA}=$ carcinoma; $\mathrm{HSIL}=$ high-grade squamous intraepithelial lesion; $\mathrm{LSIL}=$ low-grade squamous intraepithelial lesion

* Unsatisfactory smears were excluded

+ Chi squared test

¥ 323 Cases of carcinoma in CSIS data 
assessment of whom four underwent colposcopy and none required loop excision. All five women with HSIL attended subsequent colposcopic assessment and four had loop excision.

\section{Discussion}

Cervical cancer is an important health issue for women in Hong Kong. It is the eighth most common cancer in the local female population. ${ }^{11}$ Over the past three decades, the ASR of cervical cancer has declined from 25 per 100000 in 1983 to 8.7 per 100000 in $2013 .^{11}$ The figure remains higher than that of other high-income countries such as Finland $(\mathrm{ASR}=4.3$ per 100000$) .{ }^{1}$ After the organised cervical screening programme was launched, the everscreened rate increased from $37 \%$ in 2003 to $64 \%$ $2008,{ }^{12}$ and remained approximately $70 \%$ until $2014 .^{5}$ As this programme does not proactively recruit eligible women, 30\% remain never-screened. ${ }^{5}$ Studies show that these women tend to be immigrants or have a lower socio-economic status with lower family income..$^{6-9,13}$ In Hong Kong, 20\% of women belonged to these groups. In 2012, there were 1.02 million people living below the poverty line in Hong Kong; 250000 were adult women and comprised $7.3 \%$ of our female population. ${ }^{14,15}$ In 2011, there were 171322 mainlanders who had been resident in Hong Kong for less than 7 years; 80237 were women aged 25 to 54 years, comprising $2.3 \%$ of our female population. ${ }^{15,16}$ Immigrants from other ethnic groups constituted $10.2 \%$ of our female population in 2011; 7\% were South-East Asian domestic helpers from Philippines, Indonesia, and Thailand, and the remaining 3\% were South Asians from India, Pakistan, and Nepal. ${ }^{15}$ Studies show that immigrants often develop cervical cancer at rates more akin to their country of origin. ${ }^{13}$ Since these countries have a high prevalence of cervical cancer with ASR ranging from 16 to 22 per $100000,{ }^{1}$ it is not surprising that our study group had a significantly higher prevalence of cervical smear abnormalities than the comparison group (13.7\% vs $1.4 \%)$. This also explains the 6 - to 11-fold higher risk of cervical smear abnormalities in South Asian, South-East Asian, and new immigrants from Mainland China. More importantly, almost half $(42.6 \%)$ of these women had never had a cervical smear. This was particularly true for ethnic minority women $(61.2 \%)$ and new immigrants from Mainland China (45.4\%). This shows that there are inequalities in our community in the access to cervical screening, similar to most metropolitan cities worldwide. ${ }^{17,18}$ The resultant under-screening of high-risk women and over-screening of low-risk women are clearly demonstrated by the significant difference in prevalence of cervical smear abnormalities between our study group and comparison group. To ensure that cervical screening services reach these marginalised women, it is imperative to understand the barriers to screening.

Cost is a common barrier for low-income women and immigrants with economic hardship..$^{6-8,13}$ Of the female mainlanders who had been resident in Hong Kong for less than 7 years, $7.6 \%$ were in receipt of social assistance. ${ }^{16}$ Foreign domestic helpers earn only HK\$4210 a month. The charge for a cervical smear provided by the public health sector is HK\$100 and may be unaffordable by some women. Even if the screening service is free, other costs related to attending screening, such as transportation and taking time-off work, are deterrents. ${ }^{13}$ These barriers can be surmounted by community outreach that refers to the efforts made beyond the walls of the health care facility to reach target populations. ${ }^{19}$ The first step of outreach is to identify the target populations and this can be facilitated by collaboration with NGOs. ${ }^{13,19}$ Provision of a free service in mobile screening units outside working hours is also effective. ${ }^{19}$ Studies also show that the availability of female service providers helps reduce embarrassment about cervical cancer screening, and thus reluctance to attend, among Chinese and other ethnic groups. ${ }^{6-8,13,19}$ Utilising these strategies, we organised free screening events during weekends by women doctors, and we have successfully attracted almost 1200 marginalised women to participate.

Another important barrier to screening is ignorance about cervical cancer prevention and lack of awareness of screening service access, ${ }^{6-9,13,19}$ consequent to low health literacy. ${ }^{13,20}$ Health literacy refers to how easy it is for an individual to obtain, process, and understand health information and services to make appropriate health decisions. ${ }^{13}$ Low health literacy means that a person is unable to understand the health information available, access health services effectively, and make informed health decisions. ${ }^{20}$ In other words, health literacy is dependent not only on the education level and literacy of the individual, but also on how well health information is delivered and how accessible the health service is to the individual. Efforts to improve health literacy will help reduce health inequalities. ${ }^{20}$ For women with a low education level or low literacy, rewriting pamphlets in simple language or employing non-written forms of communication such as radio and television programmes are recommended. ${ }^{13,19}$ In Hong Kong, television programmes designed to promote cervical cancer screening are available, but they are broadcast in the local Cantonese dialect. ${ }^{21}$ As $68.3 \%$ of ethnic minority adults do not understand Chinese language and $36 \%$ of the new female immigrants from Mainland China do not speak Cantonese, ${ }^{22,23}$ they will not benefit from these programmes. It is worthwhile to translate these educational materials into different languages. In our recent free cervical cancer screening events, health talks on cervical cancer prevention were given 
with simultaneous translation into languages spoken by the participants, aiming to empower them to become peer health educators in their families and circle of friends, so that the health literacy in their community could be improved.

It is now known that cervical cancer is caused by human papillomavirus (HPV). Vaccination against HPV for 9- to 13-year-old girls combined with regular screening for precancerous lesions in women aged over 30 years followed by adequate treatment are now the key preventive approaches against cervical cancer. ${ }^{24}$ We have launched a free HPV vaccination programme for 9- to 18-year-old girls in this marginalised population. Since 2013, 176 girls from low-income families and 24 girls from ethnic minority groups have been vaccinated. It is hoped that our free cervical smear programme and free HPV vaccination programme will help reduce the incidence of cervical cancer in these marginalised women.

\section{Limitations}

Our study was a retrospective analysis of data obtained from our free cervical cancer screening campaign. Limited by the nature of the campaign, important information such as occupation, education level, household income, and reasons for not attending screening was not obtained. Some data on the history of cervical smear were missed due to a language barrier. Moreover, self-reported smear history may not be reliable in this group of women with low health literacy.

The comparison group may not be ideal as it may represent an ultra-low-risk population, as reflected by the low prevalence of cervical smear abnormalities in these women who had regular cervical smears. Nonetheless, this is the only accessible data set from which to obtain the necessary raw data for analysis. Moreover, limited by the scarcity of data available on the smear reports from the Well Women Clinic, the only means to avoid including women with a similar background to those in the study group was by excluding reports bearing foreign names and those with the first alphabet of the identity card number being $R, M$, or W. When we compared the prevalence of cervical smear abnormalities in the study group with the CSIS data, ${ }^{10}$ which may be more representative of the general population, the findings remained similar and the prevalence of cervical smear abnormalities remained 2-fold higher (Table 4).

It would be more informative to have data about HPV DNA testing on all abnormal smears, but unfortunately the test was not covered by the charitable fund. The picture would also be more complete if the colposcopic or histological diagnosis of those women with abnormal cervical smears was available. Such information could not be obtained without the individual's consent. We did attempt to contact these women to ensure compliance with subsequent gynaecological assessment and treatment after the event, but were successful in only $36 \%$ of cases as they came from a very mobile population.

It is encouraging that most contactable women with LSIL or HSIL did attend subsequent assessment, and almost all with HSIL received treatment. It is hoped that by identifying and treating precancerous lesions, our campaign may help reduce the incidence of cervical cancer in these marginalised women.

\section{Conclusions}

The prevalence of cervical smear abnormality in marginalised women is at least double that of the general population and almost half had never had a cervical smear. South Asian, South-East Asian, and new immigrants from Mainland China had a 6- to 11-fold increased risk of cervical smear abnormalities compared with local Chinese population. The Government should play a proactive role in developing a more comprehensive cervical cancer screening programme in Hong Kong and ensuring adequate coverage for marginalised women by developing community outreach programmes through collaboration with community NGOs.

\section{Acknowledgements}

We thank the following organisations for collaboration in the 'Ripple Action' and 'WE Stand' projects (in alphabetical order): Association of Women Accountants (Hong Kong) Ltd, GoodNews Communication International, Hepatitis Free Generation, Hong Kong Ap Lei Chau Women's Association, Hong Kong Employment Development Service, Hong Kong Federation of Women, Hong Kong Federation of Women Lawyers, Hong Kong Island Women's Association, Hong Kong Nurses General Union, Hong Kong Outlying Islands Women's Association, Hong Kong Playground Association, Hong Kong Sheng Kung Hui Lady MacLehose Centre, Hong Kong Sheng Kung Hui Welfare Council Limited, Hong Kong Women Doctors Association, International Social Service Hong Kong Branch, Kowloon Women's Organisations Federation, Narcotics Division of Security Bureau, Po Tat Women's Association, RainLily Association Concerning Sexual Violence Against Women, Social Welfare Department, The Neighbourhood AdviceAction Council, Village Volunteers of Hong Kong Sanatorium and Hospital, Yang Memorial Methodist Social Service Family Education and Support Centre, and Yuen Long Town Hall Support Service Centre for Ethnic Minorities.

We thank Dr Ellen Li Charitable Foundation for funding all the cervical smears in the 'Ripple Action' and 'WE Stand' projects. We thank Zonta Club of 
Kowloon for sponsoring all the HPV vaccines. We thank Dr KL Mak for retrieving cervical smear data for the comparison group; Prof DS Sahota for statistical support; Prof TKH Chung, Prof SSC Ho, and Prof TC Li for editorial assistance; and Prof HYS Ngan, the advisor of the 'Ripple Action' and 'WE Stand' free cervical screening projects.

\section{Declaration}

All the cervical smears taken in the "Ripple Action" and "WE Stand" projects were funded by Dr Ellen Li Charitable Foundation. All the HPV vaccines were sponsored by Zonta Club of Kowloon. All authors have disclosed no conflicts of interest.

\section{References}

1. Ferlay J, Soerjomataram I, Ervik M, et al. GLOBOCAN 2012 v1.0. Cancer incidence and mortality worldwide: IARC CancerBase No. 11. Lyon, France: International Agency for Research on Cancer; 2013. Available from: http://globocan.iarc.fr. Accessed 17 Feb 2016.

2. Denny L, Quinn M, Sankaranarayanan R. Chapter 8: Screening for cervical cancer in developing countries. Vaccine 2006;24 Suppl 3:S3/71-7.

3. Gakidou E, Nordhagen S, Obermeyer Z. Coverage of cervical cancer screening in 57 countries: low average levels and large inequalities. PLoS Med 2008;5:e132.

4. Surveillance and Epidemiology Branch, Centre for Health Protection, Department of Health, Hong Kong SAR Government. Topical health report No. 4: Prevention and screening of cervical cancer. Available from: http://www. chp.gov.hk/files/pdf/grp-THR-report4-en-20041209.pdf. Accessed 17 Feb 2016.

5. Cervical screening programme: statistics and reports. Available from: http://www.cervicalscreening.gov.hk/ english/sr/sr_statistics_ccsc.html. Accessed 17 Feb 2016.

6. Wang LD, Lam WW, Fielding R. Cervical cancer prevention practices through screening and vaccination: A cross-sectional study among Hong Kong Chinese women. Gynecol Oncol 2015;138:311-6.

7. Wang LD, Lam WW, Wu J, Fielding R. Hong Kong Chinese women's lay beliefs about cervical cancer causation and prevention. Asian Pac J Cancer Prev 2014;15:7679-86.

8. Holroyd E, Twinn S, Adab P. Socio-cultural influences on Chinese women's attendance for cervical screening. J Adv Nurs 2004;46:42-52.

9. Adab P, McGhee SM, Yanova J, Wong LC, Wong CM, Hedley AJ. The pattern of cervical cancer screening in Hong Kong. Hong Kong Med J 2006;12(Suppl 2):S15-8.

10. Cervical Screening Programme annual statistics report 2014. Available from: http://www.cervicalscreening.gov. hk/english/sr/files/2014_Eng.pdf. Accessed 17 Feb 2016.
11. Department of Health, Hong Kong SAR Government. Cervical cancer. Available from: http://www.chp.gov.hk/ en/content/9/25/56.html. Accessed 14 Sep 2016.

12. Wu J. Cervical cancer prevention through cytologic and human papillomavirus DNA screening in Hong Kong Chinese women. Hong Kong Med J 2011;17(3 Suppl 3):S20-4.

13. Schleicher E. Immigrant women and cervical cancer prevention in the United States. Available from: http:// www.jhsph.edu/research/centers-and-institutes/womensand-childrens-health-policy-center/publications/ ImmigrantWomenCerCancerPrevUS.pdf. Accessed 17 Feb 2016.

14. Lam C. Hong Kong's first official poverty line-purpose and value. Available from: http://www.povertyrelief.gov. hk/eng/pdf/20130930_article.pdf. Accessed 17 Feb 2016.

15. 2011 Hong Kong Population Census. Population by ethnicity, sex and economic activity status, 2011 (C110). Available from: http://www.census2011.gov.hk/en/maintable/C110.html. Accessed 17 Feb 2016.

16. 2011 Hong Kong Population Census. Thematic report: Persons from the Mainland having resided in Hong Kong for less than 7 Years. Available from: http://www.statistics. gov.hk/pub/B11200612012XXXXB0100.pdf. Accessed 17 Feb 2016.

17. Grillo F, Vallée J, Chauvin P. Inequalities in cervical cancer screening for women with or without a regular consulting in primary care for gynaecological health, in Paris, France. Prev Med 2012;54:259-65.

18. Moser K, Patnick J, Beral V. Inequalities in reported use of breast and cervical screening in Great Britain: analysis of cross sectional survey data. BMJ 2009;338:b2025.

19. Comprehensive cervical cancer control: a guide to essential practice. 2nd ed. Geneva: World Health Organization; 2014.

20. Kanj M, Mitic W. Promoting health and development: closing the implementation gap. Available from: http:// www.who.int/healthpromotion/conferences/7gchp/ Track1_Inner.pdf. Accessed 17 Feb 2016.

21. Twinn SF, Holroyd E, Fabrizio C, Moore A, Dickinson JA. Increasing knowledge about and uptake of cervical cancer screening in Hong Kong Chinese women over 40 years. Hong Kong Med J 2007;13(Suppl 2):S16-20.

22. 2011 Hong Kong Population Census. Thematic report: Ethnic minorities. Available from: http://www.statistics. gov.hk/pub/B11200622012XXXXB0100.pdf. Accessed 17 Feb 2016.

23. Central Policy Unit, Hong Kong SAR Government. A study of new arrivals from Mainland China; 25 Jan 2013. Available from: http://www.cpu.gov.hk/doc/en/research reports/A_study_on_new_arrivals_from_Mainland_ China.pdf. Accessed 17 Feb 2016.

24. Comprehensive cervical cancer prevention and control-a healthier future for girls and women: WHO guidance note. World Health Organization; 2013. 